\title{
Delivery of Care for Functional Gastrointestinal Disorders: A Systematic Review
}

\author{
Chamara Basnayake ${ }^{1,2}$, MD FRACP \\ Gastroenterologist \\ Michael A Kamm ${ }^{1,2}$, MD PhD \\ Professor of Gastroenterology \\ Michael R Salzberg ${ }^{1,2}, \mathrm{MD}$ \\ Associate Professor \\ Amy Wilson-O'Brien ${ }^{1,2}$, PhD \\ Clinical Scientist \\ Annalise Stanley ${ }^{1}$, BSc \\ Research Nurse \\ Alexander J Thompson ${ }^{1,2}$ MD PhD \\ Professor of Gastroenterology
}

Affiliations: 1) Department of Gastroenterology, St Vincent's Hospital, Melbourne (CB,MAK, AJT, MS, AS). 2) University of Melbourne, Melbourne, Australia (CB, MAK, MS, AWOB, AJT).

\section{Corresponding Author:}

Professor Michael A Kamm

St Vincent's Hospital

Victoria parade

FITZROY 3065

Melbourne

Australia

Tel: +61394175064

Fax: +61 394162485

This is the author manuscript accepted for publication and has undergone full peer review but has not been through the copyediting, typesetting, pagination and proofreading process, which may lead to differences between this version and the Version of Record. Please cite this article as doi: $10.1111 /$ jgh.14830

This article is protected by copyright. All rights reserved. 
Email: $\underline{\text { mamm@unimelb.edu.au }}$

This article is protected by copyright. All rights reserved. 


\section{Conflicts of interest:}

No author has any conflict of interest.

\section{Author contributions:}

$C B, M A K, M S$ and $A J T$ devised the concept. $C B$ acquired the systematic search under the supervision of MAK, MS, and AJT. CB wrote the manuscript. MAK, MS, AWOB, AS and AJT provided critical revision of the manuscript for important intellectual content.

\section{Acknowledgments:}

$C B$ is supported by the Australian Postgraduate Award and the St Vincent's Research Endowment Fund. MAK, AWOB and AS are supported by the Australasian Gastro Intestinal Research Foundation.

Keywords: irritable bowel syndrome, functional gastrointestinal disorders, outpatient specialist care, models of care, delivery of care

This article is protected by copyright. All rights reserved. 


\begin{abstract}
BACKGROUND: A diverse range of treatments are available for the treatment of functional gastro-intestinal disorders (FGIDs). Individual treatments, including drug therapies, behavioural therapy ("biofeedback"), psychological therapies, and dietary therapies have been well validated in controlled, randomised trials and real-life case series. However, few studies have evaluated models of delivery of care for the whole population of referred patients with a FGID. This review evaluates models of specialist outpatient care for the management of FGIDs.
\end{abstract}

METHODS: A systematic review was performed of full-text articles published until October 2018 in PUBMED/Medline and EMBASE. Studies were included if they evaluated a model of outpatient care in a specialist setting for the treatment of adult patients with a FGID, and included patient-reported outcomes comprising symptoms, quality of life or psychological well-being.

RESULTS: Few studies have evaluated the delivery of care for the whole population of referred patients with a FGID, and there was one randomised comparison of different models of care. Two studies that evaluated the outcome of gastroenterologist-only clinics suggested poor long-term results. Two non-comparative case series reported the outcome of multi-disciplinary care, including gastroenterologists and psychological therapists, suggesting improved patient quality of life and psychological well-being.

CONCLUSIONS: Despite the high prevalence and cost of treating FGIDs, and the availability of effective treatments, there are few data, and limited randomised comparisons, reporting the outcome of different types of specialist care. The few data available suggest that multidisciplinary care is superior to gastroenterologist-only care, but this needs to be validated in prospective comparative studies.

This article is protected by copyright. All rights reserved. 
FGIDs constitute the commonest disorders treated in gastroenterological practice ${ }^{1}$. They are associated with significant impairment in quality of life ${ }^{2}$ and psychological well-being ${ }^{3}$. They account for considerable direct costs to the patient and the healthcare system ${ }^{4}$ and secondary costs from impaired workforce productivity and absenteeism ${ }^{5}$.

The limited available evidence on outcomes from current models of care suggest that patients are often dissatisfied with prescribed therapies ${ }^{6}$, seek repeated care, are overinvestigated, try numerous therapies often with little benefit ${ }^{7}$, and may undergo surgery that is either unnecessary or of dubious efficacy ${ }^{8}$. Most of these studies report on care provided by specialist gastroenterologists only and focus on drug therapies.

There is a rich body of randomised, controlled trial evidence on the therapeutic value of specific drug treatments and non-drug therapies in the various FGIDs. Pharmacological therapies of proven value include antidepressants ${ }^{9}$, antibiotics ${ }^{10}$, aperients ${ }^{11}$ and nonlaxative bowel stimulants ${ }^{12} 1314$. Proven non-drug therapies include dietary ${ }^{15}$, behavioural ${ }^{16}$ and psychologically-based therapies ${ }^{17}$.

Despite the evidence that these therapies are also effective in real-world, single-disorder case series $^{18-20}$, there are almost no data on the extent of, and the outcome, of their use when incorporated into routine clinical care.

Prior to the current study we evaluated the outcome of care for patients with a FGID in our specialist gastroenterology clinic, based in a large, university-affiliated general hospital. This clinic is staffed only by gastroenterologists and residents and offers mainly pharmacological therapies. The symptomatic outcome of care was poor in a majority of patients ${ }^{21}$.

This article is protected by copyright. All rights reserved. 
A key question in this field therefore remains: what is the best model of specialist care for patients with a FGID? This paper aims to systematically review the outcome of different models of delivery of outpatient care for patients with a FGID. It is not intended to review the specific treatments, but rather models of delivery of care that incorporate these different treatments.

\section{METHODS}

The Preferred Items for Systematic Reviews and Meta-Analyses (PRISMA) guidelines were used for this review. The protocol of this review was prospectively registered with PROSPERO (CRD42018103584), the international prospective register of systematic reviews.

\section{Search Strategy, Study selection and Data Extraction.}

A systematic search of PubMed and EMBASE databases for English-language publications up until October 2018 was conducted. Studies published in abstract form only were excluded. Conference abstracts were not included as they did not provide sufficient information to determine if a study met inclusion criteria. Search terms are shown in table 1. FGIDs included irritable bowel syndrome, functional dyspepsia, functional constipation and faecal incontinence. Search terms addressing models of outpatient care included ambulatory care, healthcare or outcome assessment.

A model of care was defined as the routine application of a patient pathway through a service with defined criteria for patient selection for different treatments. Further the model of care had to define the stages and involvement of clinical staff and treatment modalities. This review included only hospital outpatient care for functional gut disorders, in which clinical care was provided by a gastroenterologist, surgeon, psychologist, psychotherapist, dietician, physiotherapist, nurse or gut-focused hypnotherapist. This 
review aimed to assess the value of types or models of hospital outpatient service, not of the individual treatments in isolation. This review therefore only included studies that described the treatment pathway for all patients presenting with a FGID.

The Search and title and abstract review was conducted by CB. Full text articles were reviewed and selected by $C B, A W O B, A S, M S$ and MAK. Any disagreement in selecting papers was resolved by consensus of all authors.

\section{Patient Populations}

Studies that comprised adults aged 18 years or older with a FGID, defined by the Rome ${ }^{22}$ or Manning criteria ${ }^{23}$, who had attended a specialist outpatient clinic, were included. Randomised controlled trials, observational, cross-sectional and retrospective studies were included.

\section{Outcomes}

Studies which evaluated patient outcomes after attending a specialist clinic were included. These outcomes included symptoms, quality of life and psychological wellbeing. Economic measures were not evaluated due to marked differences between countries in payment and insurance systems.

\section{Data analysis}

All studies are described in detail and summarised in Table 2. Due to study heterogeneity a meta-analysis was not performed.

This article is protected by copyright. All rights reserved. 


\section{RESULTS}

Of 13089 studies identified, 6003 duplicates were excluded, leaving 7086 studies. After examination of the titles and abstracts, a further 7032 studies were excluded. Of the 56 reports reviewed in detail, 48 were excluded, leaving eight studies included in the final analysis (Figure 1). Fifteen of the 48 excluded studies were retrospective analyses of cohorts which did not include data on patients who did not undertake treatment, or had no controlled comparator; all these reports were in the context of specialist clinics, where it was unclear how patients were selected for that intervention, what proportion of all patients they constituted, which patients declined care, and the outcomes of patients who declined the intervention. The remaining 33 studies were excluded as they were conducted in a primary care setting or did not report patient symptom or condition outcomes.

Studies were categorized according to the model of care, the FGIDs treated, treatment interventions, year of publication and country where research was conducted (Table 2).

\section{Models of care}

Models of care were heterogenous but were categorized into a) gastroenterologist-only outpatient specialist care; b) nurse-led care; c) psychological services integrated into gastroenterology clinic; and d) education about FGID to supplement routine care.

\section{Conditions observed}

Four studies included patients with irritable bowel syndrome, two studies included patients with all FGIDs, one study included patients with faecal incontinence, and one study included patients with functional constipation.

This article is protected by copyright. All rights reserved. 


\section{Outcomes}

A range of outcome measures were utilised, not allowing for direct comparison between cohorts. Symptom scales included Irritable Bowel Syndrome Symptom Severity Scale (IBSSSS) ${ }^{24}$ or Gastrointestinal Symptom Rating Scale (GSRS) ${ }^{25}$. Quality of life outcomes were measured including the Short Form 36 (SF-36) ${ }^{26}$ and the Irritable Bowel Syndrome Quality of Life score (IBS-QOL) ${ }^{27}$.

\section{Gastroenterologist-only Specialist Clinics}

Two studies evaluated the effect of standard outpatient gastroenterologist-only care for FGIDs. Both clinics were in countries where free universal healthcare was available for patients, namely the United Kingdom and Australia. Both clinics were situated in public university-affiliated hospitals.

Canavan et $\mathrm{I}^{28}$ described a cohort of patients with IBS who were seeing a gastroenterologist for the first time, and then administered a quality of life questionnaire (EuroQoL-5D) before, and three and 12 months after, the initial visit. They showed no significant difference in quality of life after treatment. Symptoms and cost of healthcare were not evaluated. There was a poor survey response rate of 42 percent at 3 months and 17 percent at 12 months.

A study from our centre ${ }^{21}$ investigated a clinic staffed only by gastroenterologists. All referrals over a 12-month period to the gastroenterology clinic were examined. All patients with a FGID were asked to complete a survey one year after their clinical care was completed. Symptoms, time absent from work and expectations of the clinical service were evaluated in addition to a medical record review. Seventy three percent of patients underwent endoscopy. Twenty-nine percent of patients had no documented treatment offered and were presumed to have received reassurance and education about their

This article is protected by copyright. All rights reserved. 
condition. At one year after the conclusion of treatment a minority of patients reported symptom improvement, while 62 percent felt their symptoms were the same or worse than before treatment. Sixty-four percent of patients were still concerned about their symptoms. Patients who had been referred to a dietician outside of the specialist clinic, and who then undertook a low-FODMAP diet, had a higher rate of symptom improvement than those who were not referred ( $53 \%$ vs $31 \%, p=0.03)$.

\section{Nurse-led care}

Nursing models of care have been evaluated in specific FGIDs both as the sole form of care and as a complement to gastroenterologist care.

Iqbal and colleagues ${ }^{29}$ described a specialised hospital clinic where patients with functional chronic constipation were managed by a nurse-led bowel training service in the context of a multi-disciplinary team. The bowel retraining service involved either a specialist nurse or physiotherapist administering a programme which included education, dietary advice, pelvic and abdominal muscle retraining, behavioural therapy relating to toileting, and psychological support. Advice was combined with tailored fibre and aperient supplementation plans tailored to each patient. Patients were seen for up to five sessions at six to eight weekly intervals. Data were collected prospectively. Sixty three percent of patients reported symptom improvement, as measured by the St Marks Satisfaction Scale and 40 percent achieved what was described as a clinically and statistically significant improvement (drop of $>1$ from baseline) in the Patient Assessment of Constipation Quality of Life Questionnaire (PAC-QoL) scores. The mean PAC-QoL score changed from 2.4 to 1.4 $(p=0.001)$, where the score ranges between 0 (best) and 4 (worst). Patients who completed four or more sessions were more likely to report satisfaction at follow up.

This article is protected by copyright. All rights reserved. 
Duelund-Jakobson et al ${ }^{30}$ evaluated a similar model of care, where a nurse-led service was offered first-line to all patients referred with faecal incontinence. This nurse-led service included the use of "biofeedback", with or without stool bulking agents, enemas and transanal irrigation. All patients who completed the treatment course achieved "satisfaction" with their status of continence on discharge and had a significant reduction in Wexner incontinence scores, from 9 to 4.9 ( $p<0.001)$. More than one year after discharge, $73 \%$ of patients remained "satisfied" with their symptoms. These positive results were achieved with a mean of one clinic appointment and one telephone follow-up.

Bengtsson et al ${ }^{31}$ prospectively evaluated a nurse practitioner providing an assessment and management plan for patients with probable IBS. The Bengtsson study involved a randomised controlled prospective trial model where patients with probable IBS referred to the tertiary hospital were assessed and seen by a nurse practitioner prior to review by the gastroenterologist. Patients randomised to standard care saw the gastroenterologist at the initial appointment. No significant differences in GSRS scores were seen between the groups, however the sample size was small, possibly due to the large number of patients subsequently being diagnosed with a condition other than IBS.

\section{Psychological services integrated into gastroenterology clinics}

Kinsinger et al $^{32}$ described a specialist clinic which included psychologists integrated into gastroenterological care, offering a range of psycho-therapeutic services. They prospectively collected data for their outpatient service. Nearly half (118 of $259-46 \%$ ) of the patients referred to the psychologist attended. Demographic variables, such as age or gender, or gut condition did not predict attendance. Eighty-seven patients continued with psychological care after their first visit. Disease-specific quality of life surveys suggested the need to avoid foods, dysphoria and anxiety about health were patients' greatest concerns. Care was predominantly gut-directed hypnotherapy (48\%) and cognitive behavioural therapy (44\%). 
Patients with a functional gut disorder who attended the psychologist had significantly fewer medical procedures after clinic attendance than those who did not see a psychologist or have hypnotherapy. There was no difference in the number of physician office visits during and after these treatments compared to those who had not had these treatments.

Kruimel et $\mathrm{al}^{33}$ described a prospectively studied cohort of patients with a complex FGID who failed standard treatments and were routinely referred to an integrated joint consultation with a psychiatrist and gastroenterologist. Of 137 referred patients 124 attended their appointment, with 72 completing questionnaires six months after the joint consultation. Of the 77 patients in their hospital catchment area who had access to psychological services, 70 were referred for medications, psychotherapy or both. The predominant medication used was citalopram. Seven patients received psychotherapy only. The commonest psychological therapy was individual psychotherapy with a psychiatrist. There were significant improvements in the 72 patients in psychological wellbeing at 6 and 12 months, as measured by the Hospital Anxiety and Depression Scale (HADS) and State Trait Anxiety Inventory (STAI-DY). There was a significant improvement in quality of life at 6 and 12 months as measured by SF-36, in both psychological and physical domain SF-36 subscores. Despite these observed improvements there were no significant reductions in gastrointestinal symptom scores at 12 months. The authors suggested that $80 \%$ of this patient population had a co-morbid psychological illness, and that the improvements in quality of life and psychological wellbeing related to the effective management of this psychological co-morbidity.

\section{Education to supplement standard specialist care}

Saito et al $^{34}$ prospectively evaluated a cohort of patients who were offered a comprehensive education programme to supplement their gastroenterological care, prior to their first visit with a gastroenterologist. This was compared to patients who did not attend an education

This article is protected by copyright. All rights reserved. 
programme. The education programme consisted of a 3-hour session run by a nurse, with dieticians, physical therapists and psychologists discussing the physiology of irritable bowel syndrome as well as self-care aspects of management. There were no significant changes in pain (measured on a visual analogue scale) or quality of life (SF-36) when comparing patients who attended the class and those who did not. The authors concluded that patients who attended the education session were more likely to have overall symptom relief than patients who did not attend ( $29 \%$ vs $7 \%$ respectively).

\section{DISCUSSION}

This review has identified that evaluation of the outcome of models of delivery of care for FGIDs is remarkably limited. The studies identified in this review were mainly retrospective; only one ${ }^{31}$ was a prospective randomised controlled trial. Very few studies have evaluated standard gastroenterologist-only care, and very few have evaluated other modalities, or integrated diverse models, of care. Where they have been evaluated, gastroenterologistonly delivery of care appears to be of limited value for many patients. The incorporation of psychologically-based therapies or education appears to have been of greater value, but direct comparisons with standard care have not been undertaken. To our knowledge there have been little or no "disease" management programmes applied to FGIDs.

This contrasts with the widespread adoption of effective 'disease management programmes' in many other areas of medicine. These programmes aim to coordinate guideline-informed outpatient care for patients with chronic diseases ${ }^{35}$. Heart failure disease management programmes were evaluated in the 1990s and showed significant reductions in hospitalisations, readmission rates, quality of life and cost ${ }^{36}$. Similar programmes in diabetes ${ }^{37}$, chronic obstructive pulmonary disease (COPD) and cirrhosis care have shown similar improved outcomes ${ }^{38,39}$.

This article is protected by copyright. All rights reserved. 
Chronic disease management programmes also address hospital readmissions and mortality, although these are not important issues for FGID's. In contrast, in FGID's key parameters are more likely to include symptom relief, patient well-being, patient satisfaction with care, and the volume of investigations and outpatient visits. Talley et al ${ }^{40}$ described FGIDs as a public health problem, related to their high prevalence, health care cost (repetitive tests and frequent specialist visits), and patient morbidity. To adequately address this public health problem, innovative models of patient management need to be evaluated, measuring these parameters. Addressing this public health problem would also allow the evaluation of non-hospital and non-specialist care of FGIDs.

There have been many reports of the outcome of non-trial, consecutive patient cohorts receiving individual therapies in specialist settings. These include gut-focused hypnotherapy ${ }^{20}$, a low-FODMAP diet in irritable bowel syndrome ${ }^{41}$, and behavioural treatment ("biofeedback") for constipation ${ }^{19}$ and faecal incontinence ${ }^{18}$. However, our systematic review identified only 8 studies in which models of care for all patients with a FGID, from referral, had been evaluated. Of these, several were retrospective or uncontrolled.

There are likely to be multiple factors that account for the lack of published data on outcomes of models of care. In the absence of accepted biomarkers for functional gut disorders, a clinical comparative evaluation of the outcome of care is difficult. New pharmacological studies are often prioritised for publication over non-pharmacological studies $^{42}$. Negative or neutral evaluations of specialist gastroenterological services may also be less likely to be published ${ }^{43}$. The two reports in this review of standard gastroenterologist-only care revealed poor patient outcomes.

There is a wealth of individual study data attesting to the benefit of psychologically-based therapies for FGIDs. Given the high prevalence of psychological co-morbidity in FGID 
patients ${ }^{3}$, it might be anticipated that psychological therapies will have an important therapeutic role in these conditions. Kruimel et $\mathrm{al}^{33}$ found greater psychological comorbidity in their FGIDs than had been appreciated previously by specialist clinicians. This underappreciation of psychological co-morbidity in FGIDs has been reported previously ${ }^{44}$ and is likely to be widespread. Kinsinger et $\mathrm{al}^{32}$ showed that integration of psychological services into specialist care is achievable and acceptable to patients; the majority of patients completed four sessions with a psychologist.

Many components of care for FGID's, such as behaviourally-based therapies, can be provided by nurses. The nursing models of care included in this review appeared to provide satisfactory results for patients with FGID's. In the case series reported by lqbal et al ${ }^{29}$ and Duelund-Jakobson et al ${ }^{30}$ nurses provided behavioural ("biofeedback") therapy, but in the context of a broader multi-disciplinary unit. Although neither of these studies had comparison cohorts, other randomised controlled trials for behaviourally-based treatment have shown superior outcomes compared to standard care ${ }^{16}$.

This review included only hospital-based clinical care. In a private clinic setting, however, Moore et al ${ }^{45}$ examined a "nurse-specialist" led clinic within a private gastroenterologist practice for patients referred with the diagnosis of IBS. A significant reduction in the number, frequency and severity of symptoms was observed after three months. There was no control group in this report.

We suggest that it would be advantageous to co-locate allied health clinicians within hospital outpatient services, alongside gastroenterologists, as part of a multidisciplinary team. This team-based approach to delivery of care can potentially address the variety of syndromes that constitute FGIDs. Including psychology and psychiatry services in a gastroenterological setting may be therapeutically helpful, given that many patients lack insight into the psychological factors that may contribute to their symptoms, are concerned

This article is protected by copyright. All rights reserved. 
by possible stigma of receiving separate psychological help, and may interpret referral to an "outside" psychological therapist as rejection ('handballing'). Integration of psychological services into gastroenterology outpatient clinics may improve the acceptability of psychological therapy if it is presented as part of routine care ${ }^{46}$, but this remains to be tested and proven. Communication between referring the gastroenterologist and allied health professionals is also likely to be enhanced. Other elements which are likely to improve the quality of care include better patient education ${ }^{34}$ and communication by treating gastroenterologists ${ }^{47}$. Improving the knowledge, communication and education of gastroenterologists in how they provide consultations for FGIDs is a further consideration that has not been examined in great detail.

In summary this review suggests that gastroenterologist-only clinics, typically with an investigational and pharmacological focus, do not often achieve positive clinical outcomes. More diverse approaches may produce better outcomes. Direct comparisons of these models of care are needed.

\section{REFERENCES}

1. Mitchell CM, Drossman DA. Survey of the AGA membership relating to patients with functional gastrointestinal disorders. Gastroenterology 1987;92:1282-4.

2. Chang L. Review article: epidemiology and quality of life in functional gastrointestinal disorders. Alimentary pharmacology \& therapeutics 2004;20 Suppl 7:31-9.

3. Mason HJ, Serrano-Ikkos E, Kamm MA. Psychological morbidity in women with idiopathic constipation. American Journal of Gastroenterology 2000;95:2852-2857.

4. Nyrop KA, Palsson OS, Levy RL, et al. Costs of health care for irritable bowel syndrome, chronic constipation, functional diarrhoea and functional abdominal pain. Alimentary pharmacology \& therapeutics 2007;26:237-48.

5. Reilly MC, Bracco A, Ricci JF, et al. The validity and accuracy of the Work Productivity and Activity Impairment questionnaire - Irritable bowel syndrome version (WPAI:IBS). Alimentary Pharmacology and Therapeutics 2004;20:459-467.

This article is protected by copyright. All rights reserved. 
6. Johanson JF, Kralstein J. Chronic constipation: a survey of the patient perspective. Aliment Pharmacol Ther 2007;25:599-608.

7. Talley NJ, Boyce PM, Jones M. Predictors of health care seeking for irritable bowel syndrome: a population based study. Gut 1997;41:394-398.

8. Longstreth GF, Yao JF. Irritable bowel syndrome and surgery: A multivariable analysis. Gastroenterology 2004;126:1665-1673.

9. Talley NJ, Locke GR, Saito YA, et al. Effect of Amitriptyline and Escitalopram on Functional Dyspepsia: A Multicenter, Randomized Controlled Study. Gastroenterology 2015;149:340-9 e2.

10. Pimentel $M$, Lembo A, Chey WD, et al. Rifaximin therapy for patients with irritable bowel syndrome without constipation. N Engl J Med 2011;364:22-32.

11. Chiarioni G, Whitehead WE, Pezza V, et al. Biofeedback is superior to laxatives for normal transit constipation due to pelvic floor dyssynergia. Gastroenterology 2006;130:657-64.

12. Lembo AJ, Schneier HA, Shiff SJ, et al. Two randomized trials of linaclotide for chronic constipation. N Engl J Med 2011;365:527-36.

13. Camilleri M, Kerstens R, Rykx A, et al. A placebo-controlled trial of prucalopride for severe chronic constipation. N Engl J Med 2008;358:2344-54.

14. Johanson JF, Morton D, Geenen J, et al. Multicenter, 4-week, double-blind, randomized, placebo-controlled trial of lubiprostone, a locally-acting type-2 chloride channel activator, in patients with chronic constipation. Am J Gastroenterol 2008;103:170-7.

15. Halmos EP, Power VA, Shepherd SJ, et al. A diet low in FODMAPs reduces symptoms of irritable bowel syndrome. Gastroenterology 2014;146:67-75 e5.

16. Norton C, Chelvanayagam S, Wilson-Barnett J, et al. Randomized controlled trial of biofeedback for fecal incontinence. Gastroenterology 2003;125:1320-9.

17. Ford AC, Quigley EM, Lacy BE, et al. Effect of antidepressants and psychological therapies, including hypnotherapy, in irritable bowel syndrome: systematic review and meta-analysis. Am J Gastroenterol 2014;109:1350-65; quiz 1366.

18. Norton C, Kamm MA. Outcome of biofeedback for faecal incontinence. Br J Surg 1999;86:1159-63.

19. Chiotakakou-Faliakou E, Kamm MA, Roy AJ, et al. Biofeedback provides long-term benefit for patients with intractable, slow and normal transit constipation. Gut 1998;42:517-21.

20. Miller V, Carruthers HR, Morris J, et al. Hypnotherapy for irritable bowel syndrome: an audit of one thousand adult patients. Aliment Pharmacol Ther 2015;41:844-55.

21. Basnayake C, Kamm MA, Salzberg M, et al. Outcome of hospital outpatient treatment of functional gastrointestinal disorders. Intern Med J 2018.

22. Drossman DA. Functional Gastrointestinal Disorders: History, Pathophysiology, Clinical Features and Rome IV. Gastroenterology 2016;150:1262-1279e2.

This article is protected by copyright. All rights reserved. 
23. Manning AP, Thompson WG, Heaton KW, et al. Towards positive diagnosis of the irritable bowel. British medical journal 1978;2:653-654.

24. Francis CY, Morris J, Whorwell PJ. The irritable bowel severity scoring system: a simple method of monitoring irritable bowel syndrome and its progress. Aliment Pharmacol Ther 1997;11:395-402.

25. Svedlund J, Sjodin I, Dotevall G. GSRS--a clinical rating scale for gastrointestinal symptoms in patients with irritable bowel syndrome and peptic ulcer disease. Dig Dis Sci 1988;33:129-34.

26. Ware JE, Jr., Sherbourne CD. The MOS 36-item short-form health survey (SF-36). I. Conceptual framework and item selection. Med Care 1992;30:473-83.

27. Patrick DL, Drossman DA, Frederick IO, et al. Quality of life in persons with irritable bowel syndrome: development and validation of a new measure. Dig Dis Sci 1998;43:400-11.

28. Canavan C, West J, Card T. Change in Quality of Life for Patients with Irritable Bowel Syndrome following Referral to a Gastroenterologist: A Cohort Study. PLoS One 2015;10:e0139389.

29. Iqbal F, Askari A, Adaba F, et al. Factors Associated With Efficacy of Nurse-led Bowel Training of Patients With Chronic Constipation. Clin Gastroenterol Hepatol 2015;13:1785-92.

30. Duelund-Jakobsen J, Haas S, Buntzen S, et al. Nurse-led clinics can manage faecal incontinence effectively: results from a tertiary referral centre. Colorectal Dis 2015;17:710-5.

31. Bengtsson $\mathrm{M}$, Ulander $\mathrm{K}$, Borgdal EB, et al. A holistic approach for planning care of patients with irritable bowel syndrome. Gastroenterol Nurs 2010;33:98-108.

32. Kinsinger SW, Ballou S, Keefer L. Snapshot of an integrated psychosocial gastroenterology service. World J Gastroenterol 2015;21:1893-9.

33. Kruimel J, Leue C, Winkens B, et al. Integrated medical-psychiatric outpatient care in functional gastrointestinal disorders improves outcome: a pilot study. Eur J Gastroenterol Hepatol 2015;27:721-7.

34. Saito YA, Prather CM, Van Dyke CT, et al. Effects of multidisciplinary education on outcomes in patients with irritable bowel syndrome. Clin Gastroenterol Hepatol 2004;2:576-84.

35. Stewart S, Wiley JF, Ball J, et al. Impact of Nurse-Led, Multidisciplinary Home-Based Intervention on Event-Free Survival Across the Spectrum of Chronic Heart Disease: Composite Analysis of Health Outcomes in 1226 Patients From 3 Randomized Trials. Circulation 2016;133:1867-77.

36. Jensen L, Troster SM, Cai K, et al. Improving Heart Failure Outcomes in Ambulatory and Community Care: A Scoping Study. Med Care Res Rev 2017;74:551-581.

37. Knight $\mathrm{K}$, Badamgarav $\mathrm{E}$, Henning JM, et al. A systematic review of diabetes disease management programs. Am J Manag Care 2005;11:242-50.

This article is protected by copyright. All rights reserved. 
38. Boland MR, Tsiachristas A, Kruis AL, et al. The health economic impact of disease management programs for COPD: a systematic literature review and meta-analysis. BMC Pulm Med 2013;13:40.

39. Morando F, Maresio G, Piano S, et al. How to improve care in outpatients with cirrhosis and ascites: A new model of care coordination by consultant hepatologists. Journal of Hepatology 2013;59:257-264.

40. Talley NJ. Functional gastrointestinal disorders as a public health problem. Neurogastroenterol Motil 2008;20 Suppl 1:121-9.

41. O'Keeffe $M$, Jansen $C$, Martin $L$, et al. Long-term impact of the low-FODMAP diet on gastrointestinal symptoms, dietary intake, patient acceptability, and healthcare utilization in irritable bowel syndrome. Neurogastroenterol Motil 2018;30.

42. van Lent $\mathrm{M}$, Overbeke J, Out HJ. Role of editorial and peer review processes in publication bias: analysis of drug trials submitted to eight medical journals. PloS one 2014;9:e104846-e104846.

43. Dickersin K, Chan S, Chalmers TC, et al. Publication bias and clinical trials. Control Clin Trials 1987;8:343-53.

44. Pinto-Sanchez MI, Ford AC, Avila CA, et al. Anxiety and Depression Increase in a Stepwise Manner in Parallel With Multiple FGIDs and Symptom Severity and Frequency. Am J Gastroenterol 2015;110:1038-48.

45. Moore JS, Gagan MJ, Perry RE. The benefits of a nurse-led service in the identification and management of symptoms of irritable bowel syndrome. Gastroenterol Nurs 2014;37:416-23.

46. Keefer L, Palsson OS, Pandolfino JE. Best Practice Update: Incorporating Psychogastroenterology Into Management of Digestive Disorders. Gastroenterology 2018;154:1249-1257.

47. Linedale EC, Chur-Hansen A, Mikocka-Walus A, et al. Uncertain Diagnostic Language Affects Further Studies, Endoscopies, and Repeat Consultations for Patients With Functional Gastrointestinal Disorders. Clin Gastroenterol Hepatol 2016;14:17351741.e1.

This article is protected by copyright. All rights reserved. 
Table 1. Criteria used for database searches.

1. Colon, irritable[MeSH Terms]

2. Irritable bowel syndrome[MeSH Terms])

3. Dyspepsia[MeSH Terms])

4. Fecal incontinence[MeSH Terms])

5. Constipation[MeSH Terms]

6. 1 OR 2 OR 3 OR 4 OR 5

7. Outcome Assessment (Health Care)"[Majr])

8. Ambulatory Care[Mesh]

9. Quality Assurance, Health Care[Mesh]

10. Follow-Up Studies[Mesh])

11. Treatment Outcome[Mesh])

12. Referral and Consultation[Mesh] 
13. 7 OR 8 OR 9 OR 10 OR 11 OR 12

14. 6 AND 13

Table 2: Studies included in systematic review.

\begin{tabular}{|c|c|c|c|c|c|c|c|}
\hline AUTHORs & YEAR & COUNTRY & MODEL OF CARE & INTERVENTION & $\begin{array}{l}\text { Type of } \\
\text { FGID }\end{array}$ & $\begin{array}{l}\text { TYPE OF } \\
\text { STUDY }\end{array}$ & OUTCOMES \\
\hline Saito et al & 2004 & USA & $\begin{array}{l}\text { Multi-disciplinary } \\
\text { Education }\end{array}$ & $\begin{array}{l}\text { Education class. } \\
\text { Nurse, dietician, } \\
\text { physical therapist } \\
\text { and psychologist }\end{array}$ & IBS & $\begin{array}{l}\text { Observational } \\
\text { cohort }\end{array}$ & $\begin{array}{l}\text { - } \text { Bowel Disease } \\
\text { Questionnaire } \\
\text { - } \quad \text { Pain Visual Analog } \\
\text { Scale } \\
\text { - } \quad \text { SF36 } \\
\text { - } \quad \text { Symptom Checklist } \\
\text { 90R }\end{array}$ \\
\hline Bengtsson et al & 2010 & Sweden & $\begin{array}{l}\text { Nursing planning } \\
\text { and assessment }\end{array}$ & $\begin{array}{l}\text { Nurse assessed and } \\
\text { planned care prior }\end{array}$ & IBS & RCT & - Gastrointestinal \\
\hline
\end{tabular}




\begin{tabular}{|c|c|c|c|c|c|c|c|}
\hline & & & & $\begin{array}{l}\text { to initial } \\
\text { consultation with } \\
\text { gastroenterologist }\end{array}$ & & & $\begin{array}{l}\text { Symptom Severity } \\
\text { Scale } \\
\text { - Psychological Well } \\
\text { Being Index }\end{array}$ \\
\hline Canavan et al & 2015 & UK & $\begin{array}{l}\text { Gastroenterology } \\
\text { specialist } \\
\text { outpatient clinic }\end{array}$ & $\begin{array}{l}\text { Specialist hospital } \\
\text { gastroenterology } \\
\text { outpatient clinic }\end{array}$ & IBS & $\begin{array}{l}\text { Prospective } \\
\text { Observational } \\
\text { Cohort }\end{array}$ & - Euro-QoL 5D \\
\hline $\begin{array}{l}\text { Duelund-Jakobson et } \\
\text { al }\end{array}$ & 2015 & Denmark & Nurse-led clinic & $\begin{array}{l}\text { Secondary hospital } \\
\text { specialist nurse led } \\
\text { clinic }\end{array}$ & $\begin{array}{l}\text { Faecal } \\
\text { Incontinence }\end{array}$ & Retrospective & $\begin{array}{l}\text { Wexner Incontinence } \\
\text { score }\end{array}$ \\
\hline lqbal et al & 2015 & UK & Nurse-led clinic & $\begin{array}{l}\text { Tertiary specialist } \\
\text { hospital nurse led } \\
\text { clinic }\end{array}$ & $\begin{array}{l}\text { Chronic } \\
\text { constipation }\end{array}$ & Retrospective & $\begin{array}{l}\text { - Patient assessment of } \\
\text { constipation quality of } \\
\text { life } \\
\text { - St Marks Patient } \\
\text { Satisfaction scale }\end{array}$ \\
\hline
\end{tabular}




\begin{tabular}{|c|c|c|c|c|c|c|c|}
\hline Kinsinger et al & 2015 & USA & $\begin{array}{l}\text { Psychologist } \\
\text { integrated into } \\
\text { Gastroenterology } \\
\text { outpatient clinic }\end{array}$ & $\begin{array}{l}\text { Secondary clinic } \\
\text { where psychologist } \\
\text { within clinic } \\
\text { referred patients } \\
\text { by } \\
\text { Gastroenterologists }\end{array}$ & $\begin{array}{l}\text { IBS and } \\
\text { Dyspepsia }\end{array}$ & Retrospective & $\begin{array}{l}\text { - } \text { Brief Symptom } \\
\text { inventory } \\
\text { - Irritable Bowel } \\
\text { syndrome Quality of } \\
\text { Life questionnaire }\end{array}$ \\
\hline Kruimel et al & 2015 & Netherlands & $\begin{array}{l}\text { Joint Psychology } \\
\text { and } \\
\text { Gastroenterology } \\
\text { clinic consultation }\end{array}$ & $\begin{array}{l}\text { Secondary clinic } \\
\text { where psychologist } \\
\text { and } \\
\text { gastroenterologist } \\
\text { provided joint } \\
\text { consultation }\end{array}$ & All FGID's & $\begin{array}{l}\text { Prospective } \\
\text { observational } \\
\text { cohort }\end{array}$ & $\begin{array}{l}\text { - } \text { Gastrointestinal } \\
\text { - } \text { Cognitive scale for } \\
\text { functional bowel } \\
\text { disorders } \\
\text { - Hospital anxiety and } \\
\text { depression scale } \\
\text { - SF-36 } \\
\text { - State trait anxiety } \\
\text { inventory }\end{array}$ \\
\hline
\end{tabular}




\begin{tabular}{|l|l|l|l|l|l|l|l|}
\hline Basnayake et al & 2018 & Australia & $\begin{array}{l}\text { Gastroenterology } \\
\text { specialist } \\
\text { outpatient clinic }\end{array}$ & $\begin{array}{l}\text { Secondary hospital } \\
\text { Gastroenterology } \\
\text { outpatient clinic }\end{array}$ & All FGID's & $\begin{array}{l}\text { Retrospective } \\
\text { cohort }\end{array}$ & $\begin{array}{l}\text { Patient self-rating of } \\
\text { symptoms }\end{array}$ \\
\hline
\end{tabular}




\section{FIGURES}

Figure 1. PRISMA Flow diagram for search on the delivery care for functional gastro intestinal disorders (FGIDs).

This article is protected by copyright. All rights reserved. 


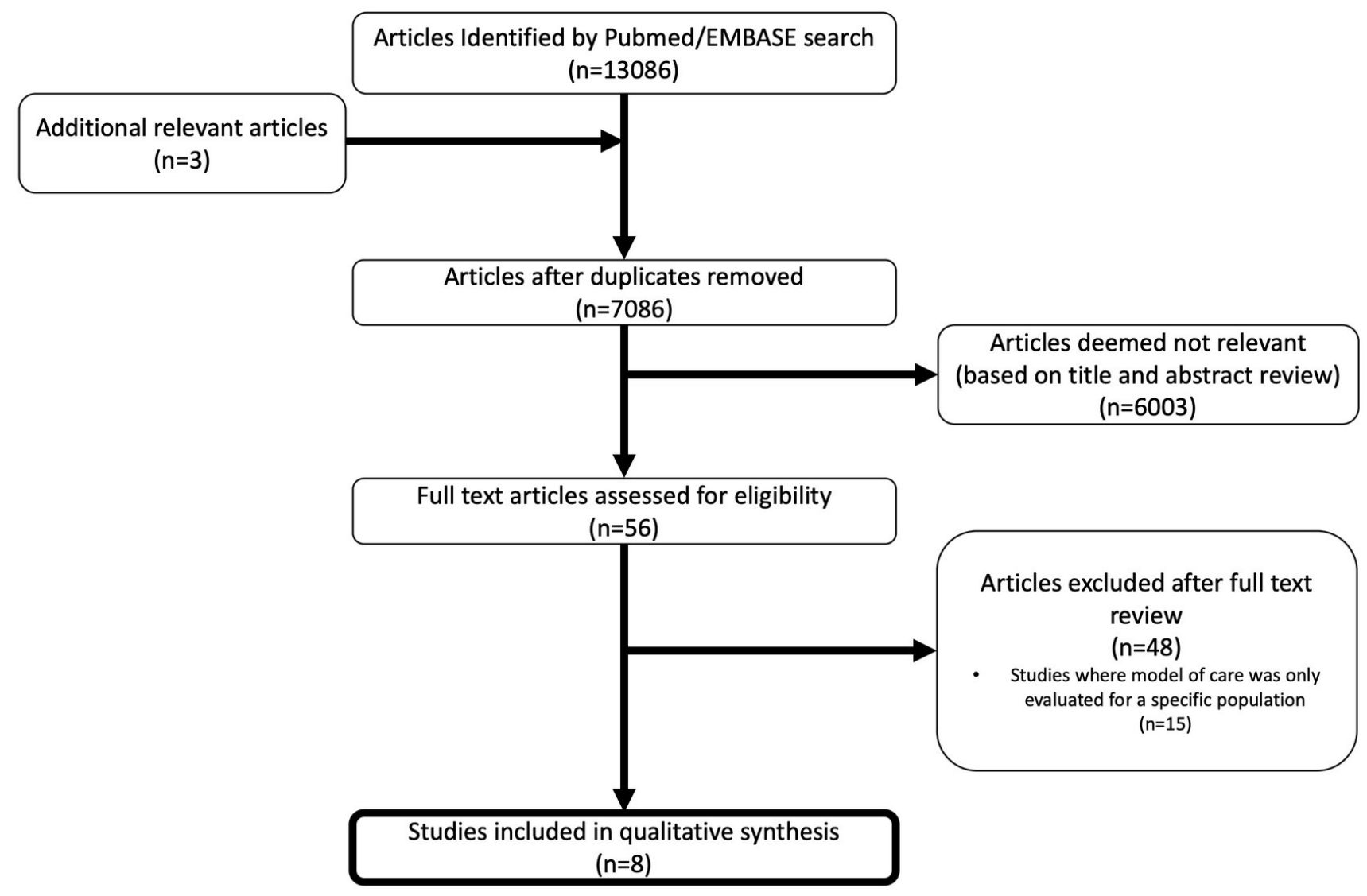

JGH_14830_f1.jpg 


\section{University Library}

\section{- M M N E R VA A gateway to Melbourne's research publications}

Minerva Access is the Institutional Repository of The University of Melbourne

\section{Author/s:}

Basnayake, C;Kamm, MA;Salzberg, MR;Wilson-O'Brien, A;Stanley, A;Thompson, AJ

Title:

Delivery of care for functional gastrointestinal disorders: A systematic review

Date:

2020-02-01

Citation:

Basnayake, C., Kamm, M. A., Salzberg, M. R., Wilson-O'Brien, A., Stanley, A. \& Thompson, A. J. (2020). Delivery of care for functional gastrointestinal disorders: A systematic review. JOURNAL OF GASTROENTEROLOGY AND HEPATOLOGY, 35 (2), pp.204-210. https:// doi.org/10.1111/jgh.14830.

Persistent Link:

http://hdl.handle.net/11343/286379 